\title{
Desain Modifikasi Apartemen One East dengan Menggunakan Precast Dual System Sesuai dengan Peraturan ACI 318M-14
}

\author{
Vincentius Felix Susanto, Faimun, dan Tavio \\ Departemen Teknik Sipil, Fakultas Teknik Sipil, Lingkungan dan Kebumian, Institut Teknologi Sepuluh Nopember \\ (ITS) \\ e-mail: tavio@ce.its.ac.id
}

\begin{abstract}
Abstrak-Beton pracetak merupakan metode yang digunakan pada perancangan bangunan selain cara pengecoran dengan metode konvensional. S eiring dengan perkembangannya, metode pracetak kini semakin banyak digunakan. Tingkat kecepatan pembangunan dan kontrol kualitas merupakan keunggulan utama metode pracetak. Perencanaan Gedung Apartemen One East Surabaya pada kondisi sebenarnya dirancang menggunakan metode konvensional dengan ketinggian 33 lantai dan 3 buah basement. Dalam studi ini, gedung tersebut akan dilakukan perancangan menggunakan metode pracetak. Pemilihan metode pracetak didasari oleh kecepatan pelaksanaan, kontrol kualitas mutu yang tinggi, ramah lingkungan, serta pengurangan jumlah tenaga kerja. Metode pracetak diterapkan pada elemen-elemen struktur primer, seperti pelat, balok, tangga, kolom dan shearwall. Dalam perencanaan struktur pada studi ini, metode menggunakan peraturan seperti perencanaan beton secara konvensional sesuai dengan SNI 2847:2013, PCI Handbook dan beberapa referensi lainnya. Selain perencanaan elemen struktur sendiri, perlu dilakukan perencanaan sambungan untuk menyambungkan elemen-elemen tersebut. Metode penyambungan yang digunakan berdasarkan dari beberapa sumber seperti, produk dari Peikko Group, dan jurnal "Horizontal Connection for Precast Concre te Shear Wall Subjected to Cyclic Deformations". Analisis perhitungan sambungan pada balok berdasarkan pada kekuatan aksial sambungan yang dibandingkan dengan kekuatan tulagan setelah mengalami leleh serta panjang penyaluran. Untuk analisa kekuatan sambungan pada kolom dan shearwall, digunakan peraturan ACI $318 \mathrm{M}-14$ dimana nilai $\phi \mathrm{Sn} \geq 1,4 \mathrm{Se}$ sedangkan $\phi \mathrm{Mn} \geq 0,4 \mathrm{Mpr}$.
\end{abstract}

Kata Kunci-Beton Pracetak.

\section{PENDAHULUAN}

$\mathrm{G}$ EDUNG Apartemen One East di Surabaya merupakan struktur bangunan beton bertulang dengan total lantai sebanyak 33 lantai dengan 3 basement dengan lokasi di Jl. Dr. Ir. Soekarno, MERR Surabaya. Desain yang sudah ada dari Apartemen One East akan diganti dengan struktur desain baru menggunakan precast dual sistem dimana seluruh bagian apartemen menggunakan beton precast baik balok, pelat, kolom, tangga dan shearwall. Ketinggian total dan jumlah lantai juga akan dimodifikasi sehingga total ketinggian menjadi $75,5 \mathrm{~m}$ dengan jumlah lantai 21 serta hanya memiliki 1 basement.

Pada perencanaan beton precast, perlu diperhatikan sambungan-sambungan yang digunakan. Jenis sambungan yang dipakai dalam perencanaan gedung ini adalah MODIX
Coupler yang disediakan oleh Peikko Group serta NMB Splice Sleeve. MODIX Coupler digunakan untuk menyambung elemen balok dan kolom, sedangkan $N M B$ Splice Sleeve digunakan untuk menyambung antar elemen kolom dan shearwall. Digunakan juga PCs Hidden Corbel untuk mengakomodasi sambungan antara balok dan shearwall pracetak. Untuk perencanaan sambungan half-slab dan balok, digunakan sambungan overtopping. Jenis sambungan ini digunakan karena tergolong monolit dengan hysteresis curve yang hampir sama dengan sambungan monolith.

Tujuan dari perencanaan Gedung Apartemen One East ini adalah untuk mampu merencanakan struktur gedung bertingkat tinggi dengan menggunakan metode beton pracetak dengan perencanaan sambungan yang monolit

Batasan masalah dari perencanaan ini adalah

1. Proyek yang digunakan adalah Apartemen One East Surabaya Setinggi 21 lantai dan 1 basement

2. Perencanaan menggunakan teknologi beton pracetak (non prategang) pada semua elemen struktur.

3. Perencanaan tidak memperhitungkan penulangan plat, tidak meninjau segi produksi beton pracetak, segi analisis anggaran, biaya dan manajemen konstruksi, dan tidak memperhitungkan electrical serta plumbing.

4. Menggunakan program bantu ETABS, AutoCad, sketchUp serta spColumn

\section{TINJAUAN PUSTAKA}

Definisi Beton Pracetak adalah struktur beton yang dicetak di luar situs proyek yang jauh dari pusat kota sehingga lebih mudah diakses. Beton pracetak lebih mudah diaplikasikan karena tidak diperlukan pengecoran in-situ, akan tetapi perlu diperhatikan kebutuhan sambungan pada beton pracetak tersebut [1]

\subsection{Precast Shear-Wall}

Precast Shear-wall memiliki kemampuan yang baik untuk struktur yang tidak terlalu tinggi dan lebih mudah untuk dibuat serta lebih efisien secara struktural, akan tetapi dibutuhkan perhatian khusus dalam penyambungan precast shear-wall dikarenakan sifat struktur yang cenderung tidak monolit [2].

2.2. Sambungan Antar Shear Wall Pracetak

"Horizontal Connection using Partially Unbonded Reinforcing Bar with NMB Splice Sleeve" [3]. 
Sambungan tipe ini menggunakan tulangan yang di sambungan dengan menggunakan NMB Splice Sleeve sesuai dengan ukuran tulangannya. Kemudian pada bagian atas sambungan diberikan plastic sheathing dengan panjang yang direncakanan yaitu $600 \mathrm{~mm}$. Sambungan tipe ini memiliki daktilitas mencapai nilai 6 .

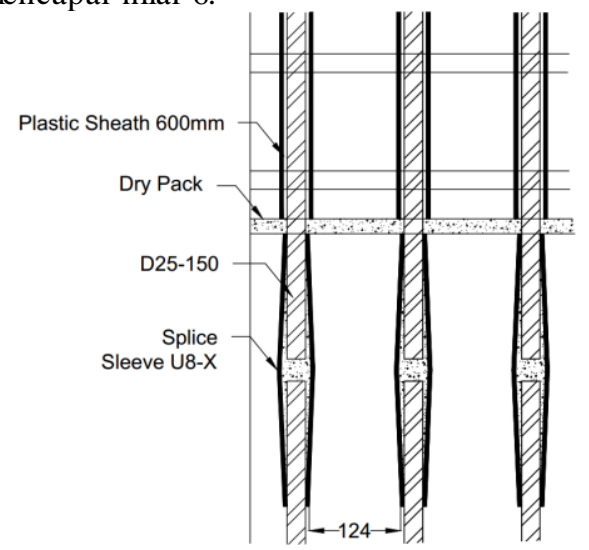

Gambar 1. Connection using Partially Unbonded Reinforcing Bar with NMB Splice Sleeve

\section{KONSEP PERENCANAAN}

Dasar-dasar perencanaan mencakup segala sesuatu baik berupa data-data teknis lapangan, asumsi perencanaan dan metode-metode yang digunakan dalam merencanakan yang dapat dimanfaatkan. Struktur bangunan asli dari Apartemen ONE EAST Surabaya adalah sistem beton konvensional (beton bertulang biasa). Studi ini bertujuan untuk merencanakan struktur bangunan aslinya dengan menggunakan metode pracetak pada balok dan kolom serta penambahan shearwall pracetak

Data dari bangunan asli yang digunakan meliputi gambar denah, data tanah, tinggi dan ukuran kolom, luasan lantai, tinggi total struktur, dimensi arah panjang dan arah lebar serta data-data lainnya.

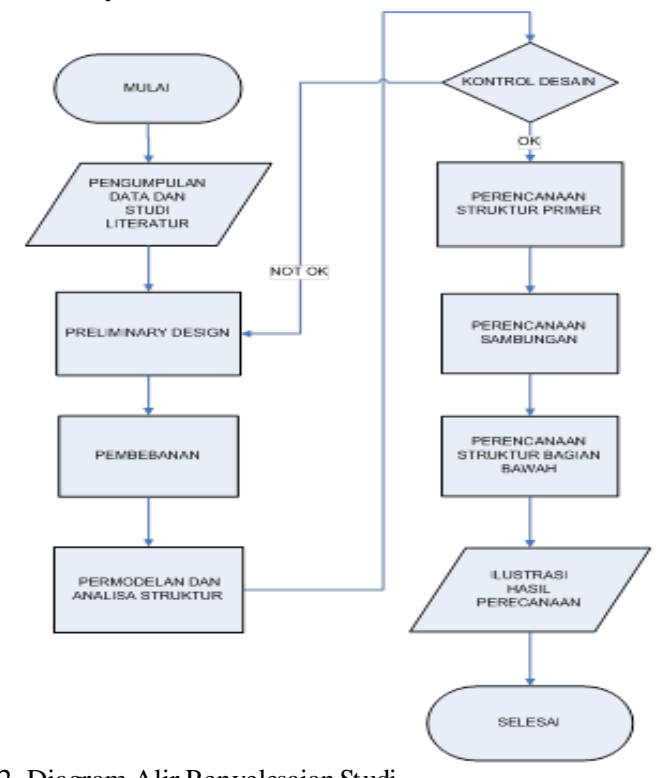

Gambar 2. Diagram Alir Penyelesaian Studi

\section{PRELIMINARY DESAIN}

\section{A. Data Perencanaan}

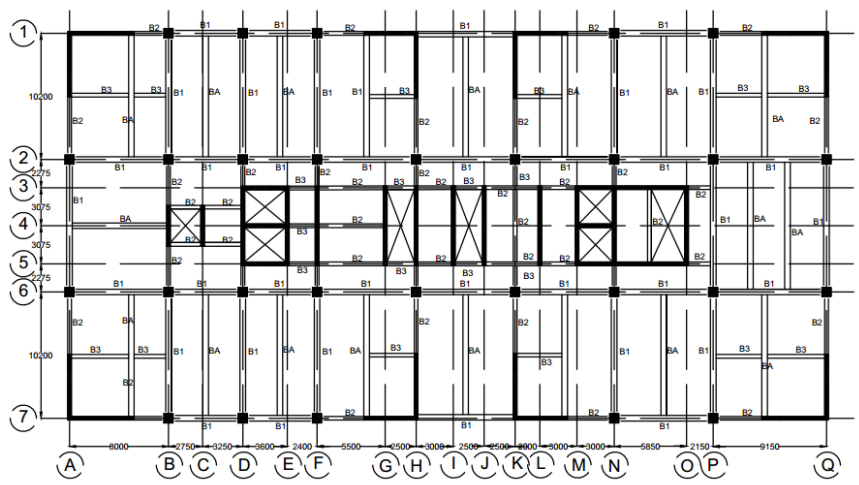

Gambar 3. Denah dan Potongan Gedung

Data perencanaan gedung beton bertulang menggunakan sistem beton pracetak sebagai berikut :

- Fungsi Bangunan

: Gedung Apartemen

- Lokasi

: Jalan Dr. Ir. Soekarno

Surabaya

- Jumlah Lantai

: 21 Lantai dan 1

basement

- Ketinggian Lantai

a. Lantai Basement : $4.00 \mathrm{~m}$

b. Lantai $1 \quad: 5.00 \mathrm{~m}$

c. Lantai 2-21 : $3.50 \mathrm{~m}$

- Tinggi Bangunan $\quad: 75.5 \mathrm{~m}$

- Mutu Beton (f'c) : $40 \mathrm{MPa}$

- Mutu Baja (fy) : $420 \mathrm{MPa}$

\section{B. Perencanaan Dimensi Balok}

Dimensi Balok Induk direncanakan dengan

$h_{\text {min }}=\frac{L}{16}, b=\frac{2}{3} h$

Sehingga didapatkan hasil sebagai berikut

Digunakan Balok Induk $130 / 45$ cm (6 m)

Digunakan Balok Induk 2 45/65 cm(10,7m)

\section{Perencanaan Dimensi Balok Anak}

Dimensi Balok Anak direncanakan dengan:

$h_{\text {min }}=\frac{L}{21}, b=\frac{2}{3} h$

Sehingga didapatkan hasil sebagai berikut

Digunakan Balok Anak 45/65 cm (10,2m)

\section{Perencanaan Dimensi Kolom}

Perencanaan dimensi kolom yang tinjau adalah kolom yang mengalami pembebanan terbesar, yaitu kolom yang memikul bentang $750 \times 600 \mathrm{~cm}$.

- Lantai 11-21

Beban berfaktor 1,2 DL + 1,6 LL $=745589 \mathrm{~kg}$

Digunakan dimensi kolom $75 \times 75 \mathrm{~cm}$

- Lantai Basement-10

Beban berfaktor + Beban Lt. 11-21 $=1538372 \mathrm{~kg}$

Digunakan dimensi kolom 100 x $100 \mathrm{~cm}$ 


\section{PEMBEBANAN DAN ANALISA STRUKTUR}

Dalam perhitungan dan analisis gempa suatu permodelan struktur, perlu dilakukan beberapa kontrol untuk memastikan permodelan tersebut benar dan bisa dianggap sesuai dengan kenyataannya.

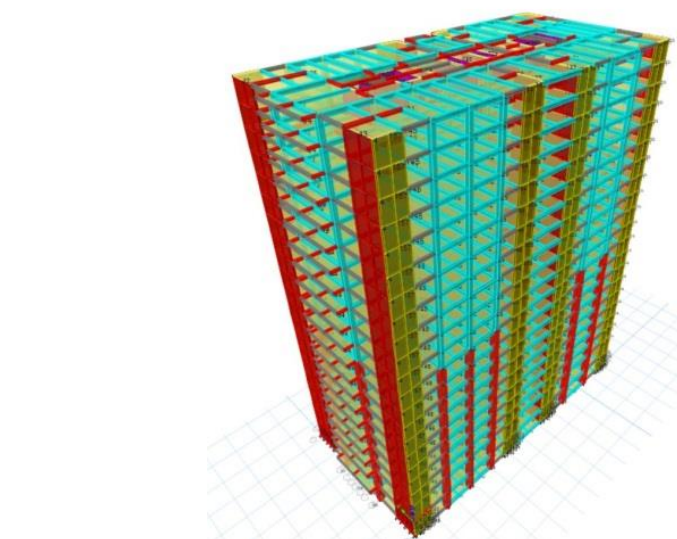

Gambar 4. Permodelan ETABS

\section{A. Pembebanan Gravitasi}

Pembebanan gravitasi berupa beban mati dan beban hidup yang bekerja pada gedung. Beban mati dan beban hidup yang diperhitungkan berdasarkan pembebanan PPIUG 1983.

Dari analisa pembebanan gravitasi, didapatkan perhitungan total beban secara manual (1D+1L) sebesar 56.532.221,2 kg sedangkan dari total perhitungan ETABS didapatkan 54.280.640,43. Sehingga dapat kita hitung selisihnya.
$\mathrm{W}_{\text {total }}$ ETABS
$=56532221,22$
$\mathrm{W}_{\text {total }}$ Perhitungan Manual
$=54280640.43$
Selisih antara keduanya$$
=3,9 \%
$$

Maka dapat dikatakan bahwa pembebanan gravitasi pada ETABS sudah benar

\section{B. Pembebanan Gempa Dinamis}

Pembebanan dinamis mengacu pada SNI 1726:2012, yang didalamnya terdapat ketentuan dan persayaran perhitungan beban gempa. Nilai Ss dan Sds pada kelas situs kategori D di Surabaya adalah sebesar 0.607 dan 0.496. Dari kategori tersebut, gedung direncanakan menggunakan Sistem Ganda yaitu Dinding Geser Beton Bertulang Khusus dan Sistem Rangka Pemikul Momen Khusus.

Dari hasil analisa program bantu ETABS, didapatkan hasil analis a periode fundamental gedung pada mode shape pertama sebesar 2.905. Nilai $\mathrm{T}$ tidak boleh melebihi hasil koefisien untuk batasan atas periode yang dihitung dari peraturan SNI 1726:2012

$$
\begin{gathered}
T_{a \text { manual }}<T_{a \text { ETABS }}<C_{u} \times T_{a} \\
2.283 \mathrm{~s}<2.905 \mathrm{~s}<3.1965 \mathrm{~S} \ldots . O K
\end{gathered}
$$

Sehingga besar Cs yang diambil sebesar 0.03375 untuk perhitungan gempa. Nilai berat seismic efektif banungan didapatkan sebesar $52.760 .457 \mathrm{~kg}$. Dari nliai tersebut ditentukan gaya gempa yang terjadi

$$
\begin{aligned}
& V=C_{s} \times W \\
& V=0,03375 \times 52760457 \mathrm{~kg}=1780981 \mathrm{~kg}
\end{aligned}
$$

Nilai $\mathrm{V}$ menjadi patokan untuk melihat nilai geser dasar yang terjadi pada base apakah sudah sesuai atau belum. Apabila nilai Vt yang didapat pada permodelan lebih kecil daripada $0,85 \mathrm{~V}$, maka scale factor gempa perlu dikalikan dengan $0,85 \mathrm{~V} / \mathrm{Vt}$.

\subsection{KONTROL DUAL SYSTEM}

Dari hasil analisa struktur menggunakan program bantu ETABS didapatkan gaya geser sebesar $V x=1.514 .209$ dan $\mathrm{Vy}=1.516 .731 .72$. Nilai-nilai tersebut sudah melebihi $0,85 \mathrm{~V}$.

Sistem Rangka Pemikul Momen harus memikul minimum $25 \%$ dari beban geser nominal total yang bekerja dalam arah kerja beban tersebut. Berikut total reaksi perletakan SRPM dan shearwall

Tabel 1.

Total Reaksi Perletakan yang Menahan Beban Gempa

\begin{tabular}{ccccc}
\hline \hline \multirow{2}{*}{ Pemikul Gaya Geser } & Gempa X & \multicolumn{2}{c}{ Gempa Y } \\
& $\mathrm{Kg}$ & $\%$ & $\mathrm{Kg}$ & $\%$ \\
\hline Shear Wall & $1.094 .773,685$ & $73 \%$ & $1.114 .797,82$ & $74 \%$ \\
SRPM & $413.379,27$ & $27 \%$ & $401.933,9$ & $26 \%$ \\
Total & $1.514 .209,8$ & & $1.516 .731,72$ & \\
\hline \hline
\end{tabular}

Dari total perhitungan di atas, dapat kita lihat bahwa komponen shearwall menahan $70-75 \%$ dari total gaya gempa yang terjadi. Sehingga konfigurasi struktru gedung telah memenuhi syarat sebagai struktur dual system.

\section{PERENCANAAN STRUKTUR SEKUNDER}

\subsection{STRUKTUR BASEMENT}

Pada perencanaan struktur basement, perencanaan dibagi menjadi 2, perencanaan pelat dan perencanaan dinding basement. Untuk perencanaan pelat perlu dipehatikan gaya uplift yang terjadi pada bagian bawah pelat. Dari perhitungan gaya uplift tersebut didapatkan ketebalan minimum pelat sebesar $350 \mathrm{~mm}$.

Pada struktur Apartemen One East telah digunakan Contiguous Bored Pile di sekeliling basement. Sehingga diding basement tidak berfungsi sebagai retaining wall.

\subsection{PERENCANAAN PENULANGAN TANGGA}

Tangga pada perencanaan ini dimodelkan sebagai frame statis tertentu yang diletakkan pada 2 perletakan sendi di bordes. Struktur tangga dari atas ke bawah tipikal.

- Tinggi Lantai : $350 \mathrm{~cm}$

- Lebar Tangga $\quad: 120 \mathrm{~cm}$

- Tebal pelat tangga(tp) $\quad: 15 \mathrm{~cm}$

- Tebal pelat bordes : $15 \mathrm{~cm}$

- Tebal pelat rata - rata $\quad: 22 \mathrm{~cm}$

Dari analisa didapatkan

Penulangan Pelat Tangga dan Bordes Penulangan Longitudinal : D10-125 Penulangan Susut : D10-200

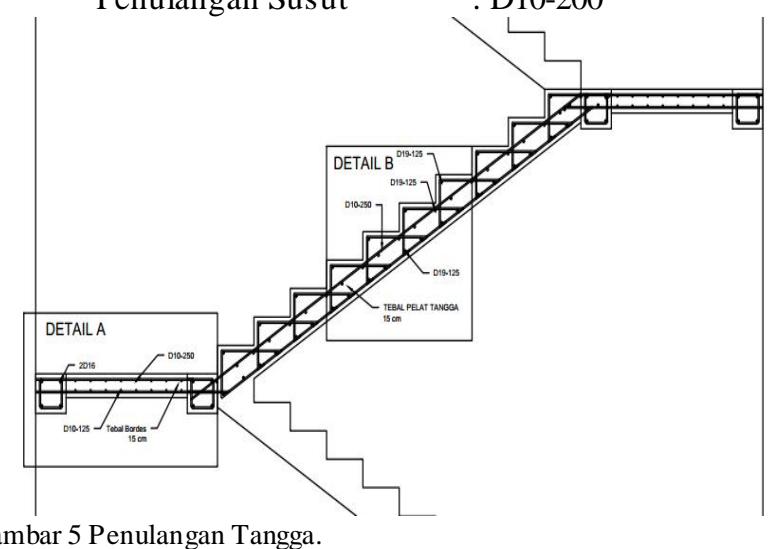

Gambar 5 Penulangan Tangga. 


\subsection{PERENCANAAN BALOK ANAK}

Dalam perhitungan balok anak, dilakukan perhitungan sebelum komoposit dan perhitungan sesudah komposit

- Dimensi Balok Anak

- Tulangan Lentur

- Tulangan Sengkang

Dari analisa yang telah dilakukan didapatkan

Tulangan Lentur

Sebelum Komposit Sesudah Komposit

$(45 \times 50 \mathrm{~cm})$

Tumpuan 2 D25

$(45 \times 65 \mathrm{~cm})$

Tumpuan 3D25

Lapangan 2 D25

Tulangan Geser

Sebelum Komposit Sesudah Komposit

$(45 \times 50 \mathrm{~cm}) \quad(45 \times 65 \mathrm{~cm})$

D13-100

D13-100

\section{PERENCANAAN STRUKTUR PRIMER}

Perencanana balok induk pada Apartemen One East menggunakan 2 dimensi balok induk

Data Perencanaan

$\begin{array}{ll}\text { Diameter Tulangan Utama } & =25 \mathrm{~cm}\end{array}$

Diameter Tulangan Sengkang $\quad=13 \mathrm{~cm}$

Balok Tipe 1 dengan dimensi 45 x $50 \mathrm{~cm}$ sebelum komposit dan 45 x $65 \mathrm{~cm}$ sesudah komposit sedangkan Balok Tipe 2 dimensinya $30 \times 30 \mathrm{~cm}$ sebelum komposit sedangkan sesudah komposit ukurannya menjadi $30 \times 45 \mathrm{~cm}$. Dari hasil analisa studi ini didapatkan

Tulangan Lentur

Sebelum Komposit Sesudah Komposit

$(45 \times 50 \mathrm{~cm}) \quad(45 \times 65 \mathrm{~cm})$

Tumpuan 2 D25 Tumpuan 7D25

Lapangan 2 D25 Lapangan 4D25

Tulangan Geser

Sebelum Komposit Sesudah Komposit

$(45 \times 50 \mathrm{~cm}) \quad(45 \times 65 \mathrm{~cm})$

4D13-100 2D13-100

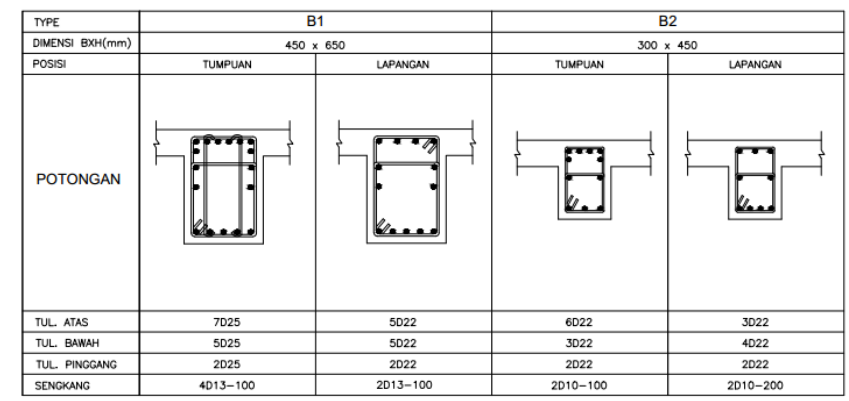

Gambar 6 Rekapitulasi Penulangan Balok

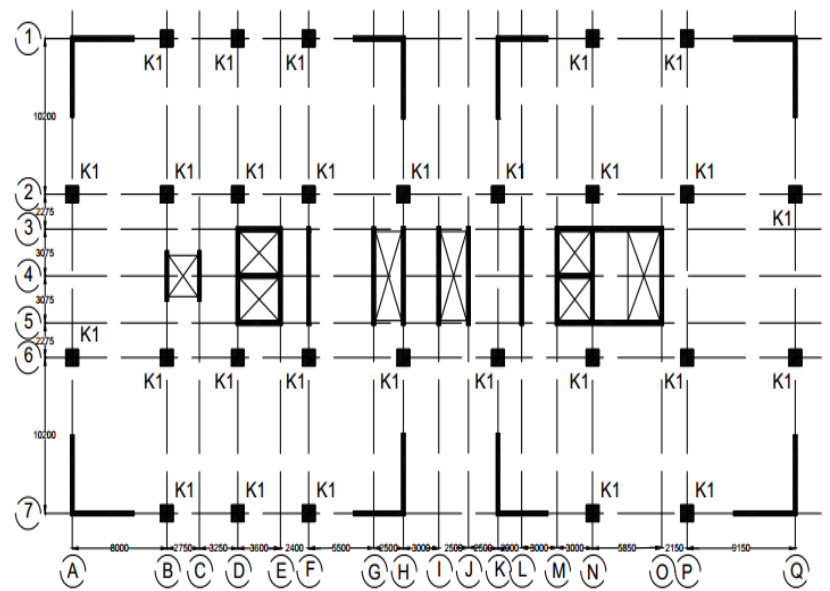

Gambar 7. Denah Kolom

Dimensi kolom Lt. B1-10 : 100/100 cm

Dimensi Kolom Lt.11-21 : 75/75 cm

Dari hasil analisa didapatkan

Setelah dilakukan analisa didapatkan bahwa

K1 : $\quad$ Tulangan Utama :8D32

Tulangan Sengkang

Sendi Plastis

:4D13-100mm

Luar Sendi Plastis $\quad$ :4D13-150

K2 : Tulangan Utama $\quad: 8 D 25$

Tulangan Sengkang

Sendi Plastis

Luar Sendi Plastis

:4D13-100mm

:4D13-150

\subsection{PERENCANAAN DINDING GESER}

Seluruh dinding geser menahan $75 \%$ gaya gempa yang disalurkan ke struktur bangunan. Ada 3 jenis segment dinding geser yang direncanakan untuk mengakomodir kebutuhan shearwall precast yaitu

1. Tipe $1=3150 \times 300 \times 3500 \mathrm{~mm}$

2. Tipe $2=2500 \times 300 \times 3500 \mathrm{~mm}$

3. Tipe $3=2000 \times 300 \times 3500 \mathrm{~mm}$

Berdasarkan hasil permodelan didapatkan gaya aksial dan momen yang bekerja sebesar:

Gaya aksial Ult $\quad: 5513,84 \mathrm{kN}$

Momen Ultimate $\quad: 4235 \mathrm{kNm}$

Geser : 2156,8 kN

Perhitungan penulangan dinding geser menggunankan spColumn dengan input gaya dari ETABS sehingga hasilnya Penulangan Diding Geser

Tulangan Vertikal 2D25-150

Tulangan Horizontal 2D25-150

Penulangan Komponen Batas

Tulangan Sengkang 2D16-100 

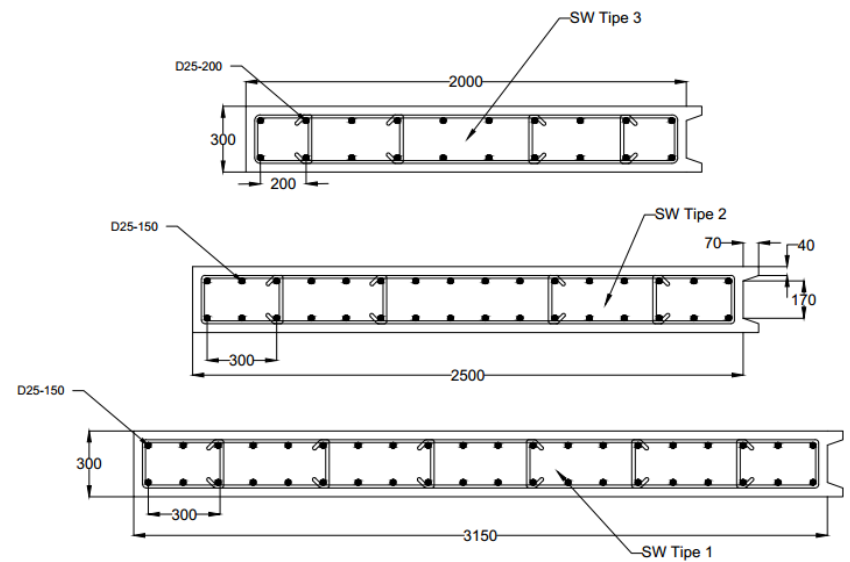

Gambar 8. Segment Shearwall

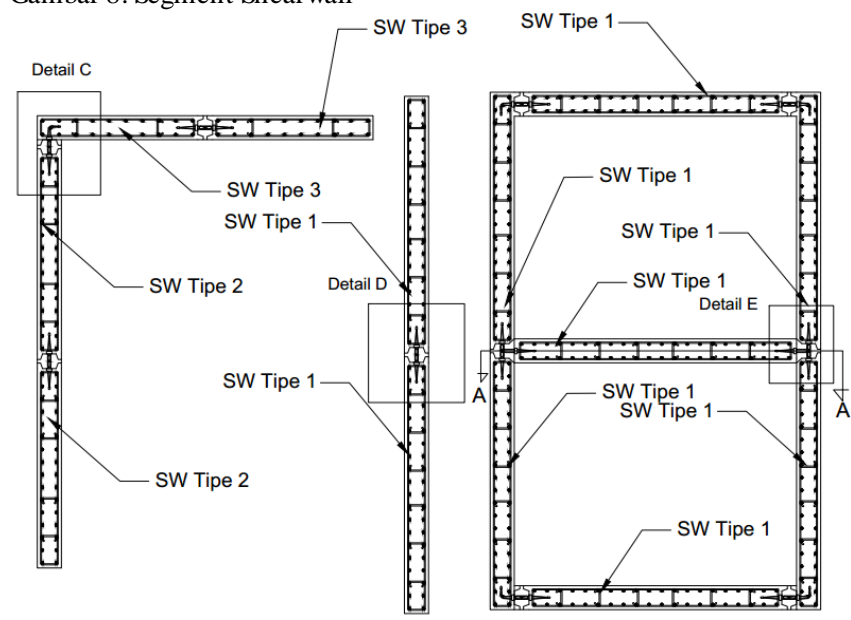

Gambar 9. Shearwall

\section{PERENCANAAN SAMBUNGAN}

Konsep desain sambungan ini menggunakan gabungan dari beberapa sambungan yang diproduksi oleh Peikko Group dan sambungan NMB Splice Sleeve.

Sambungan balok ke kolom menggunakna bantuan perancah dengan jarak $1 / 4$ dari panjang balok pada masing-masing ujungnya dan konsol pendek. Tulangan atas menggunakan MODIX SM25A P12-750(450) PM 25 SM25B P-1300 dan bawah menggunakan MODIX SM25A L-450 PM 25 SM25B P-1300 dengan kemampuan tarik 294,4 kN > 257,7 $\mathrm{kN}(1.25$ fy)

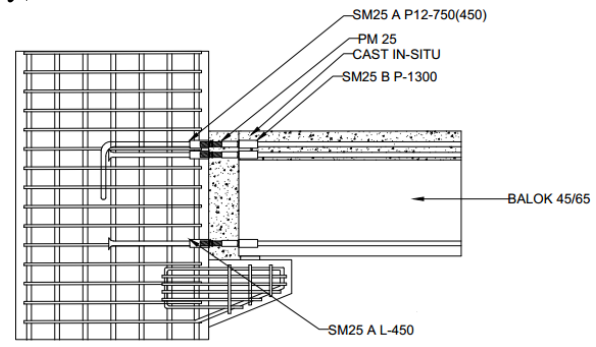

Gambar 10. Sambungan Balok ke Kolom.

Sambungan Balok Induk-Anak

Sambungan balok ke kolom menggunakna bantuan perancah dengan jarak $1 / 4$ dari panjang balok pada masing-masing ujungnya dan konsol pendek. Tulangan atas dan bawah menggunakan MODIX SM25A P12-500(200) PM 25
SM25B P-1300 dengan kemampuan tarik 294,4 kN > 257,7 $\mathrm{kN}$ (1.25 fy).

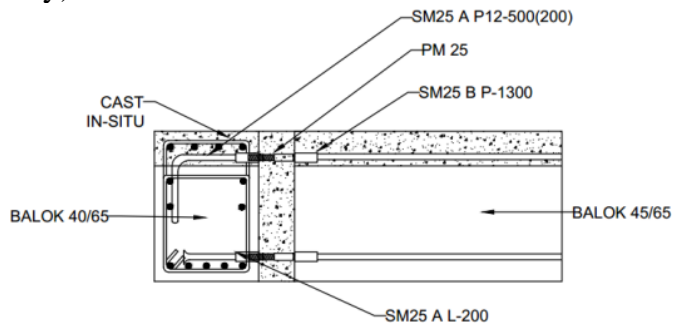

Gambar 11. Sambungan Balok Anak ke Balok Induk

\subsection{SAMBUNGAN BALOK TANGGA- SHEARWALL}

Karena posisi tangga yang terletak di antara shearwall dan shearwall pada studi ini menggunakan shearwall pracetak maka digunanak sistem sambungan khusus PCs Corbel dan PC Beam Shoe yang disediakan oleh Peikko Group. Digunakan PCs Corbel tipe PCs 200 dengan kapasitas Vrd $230 \mathrm{kN}>40,41 \mathrm{kN}(1,25 \mathrm{Vu})$ dengan Beam Shoe tipe PC 2-L.

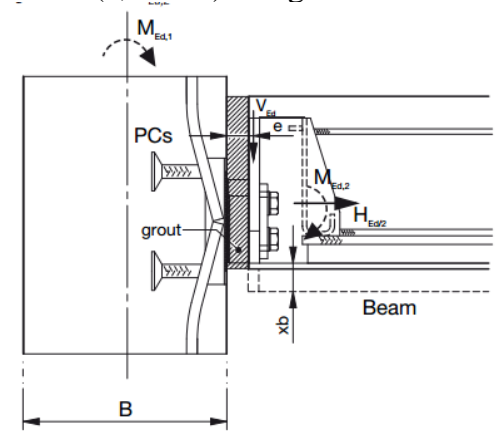

Gambar 12. Illustrasi Sambungan Balok Tangga ke Shear-wall

\subsection{SAMBUNGAN ANTAR KOLOM PRACETAK}

Sambungan antar kolom pracetak menggunakan $N M B$ Splice Sleeve dengan tipe splice sleeve sesuai dengan diameter tulangan yaitu $U X-8$. Sambungan ini telah memenuhi ACI $318 \mathrm{M}-14$ dimana $\mathrm{Mn}=4218,45 \mathrm{KNm}>0,4 \mathrm{Mpr}=1781,6$ $\mathrm{KNm}$ dan $\phi \mathrm{Vn}=3512.56 \mathrm{kN}>\mathrm{Ve}=250,08 \mathrm{Kn}$.

Sambungan Antar Shearwall Pracetak

Pada perencanaan shearwall pracetak, perlu dipersiapkan sambungan yang pas agar shearwall mampu menjadi struktur yang monolith. Sambungan yang dibutuhkan ada 2, sambungan horizontal dan sambungan vertikal.

Sambungan horizontal pada perencanaan apartemen ini didasarkan pada jurnal "Horizontal Connection for Precast Concrete Shear Walls Subjected to Cyclic Deformations Part 1 : Mild Steel" [3]. Sambungan ini terdiri dari tulangan utama yang disambung menggunakan splice sleeve kemudian digrouting. Pada jarak $600 \mathrm{~mm}$ dari pangkal sambungan dipasang plastic sheath untuk memberikan efek partially unbonded.

Kekuatan sambungan didapatkan dengan perhitungan Plastic Centroid. Kekuatan ini kemudian dibandingkan dengan momen serta tarik yang terjadi sesuai ACI 318M-14 sehingga didapatkan

$\mathrm{Sn} \geq 1,4 \mathrm{Se}$

$24.045,1>1,4 \times 5.513,84 \mathrm{kN}$

$24.045,1 \geq 7.719,37 \mathrm{kN} \ldots$ OK 
$M n \geq 0,4 \mathrm{Mpr}$

$24.734 \geq 0,4 \times 14.906,26$

$24.734 \geq 5962,4 \mathrm{kNm} \ldots$ OK

$\phi M n \geq M u$

$0,85 \times 24,734.49 \geq 4235 \mathrm{kN}$

$21.024,325 \geq 4235 k N \ldots$ OK

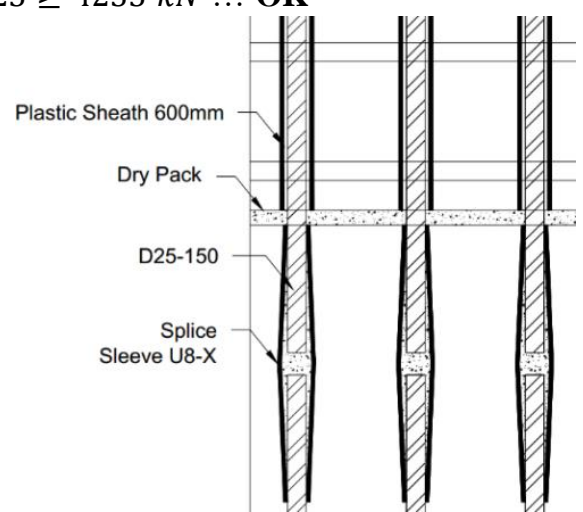

Gambar 13. Sambungan Horizontal Shear Wall

Sambungan vertikal direncanakn menggunakan $P V L$ Connecting Loop yang disediakan oleh Peikko Group. Sambungan ini menahan gaya geser yang tegak lurus dengan permukaan dinding shearwall. Jarak antar masing-masing $P V L$ Connecting Loop yang digunakan adalah $350 \mathrm{~mm}$ sehingga kekuatan yang dimiliki sebesar $209 \mathrm{Kn} / \mathrm{M}>185,31(1,25 \mathrm{Vu})$.

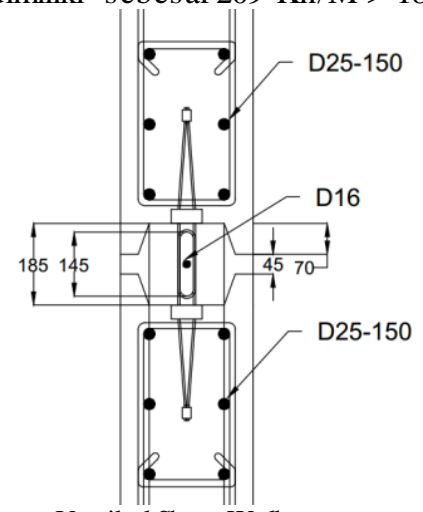

Gambar 14. Sambungan Vertikal Shear Wall

\section{PERENCANAAN PONDASI}

Pondasi pada gedung ini derencanakan menggunakna pondasi tiang pancang yang diproduksi oleh PT. WIKA Beton. Kombinasi beban yang digunakan untuk permodelan adalah beban nominal dengan desain tegangan ijin sedangkan untuk poer menggunakan kombinasi beban terfaktor.

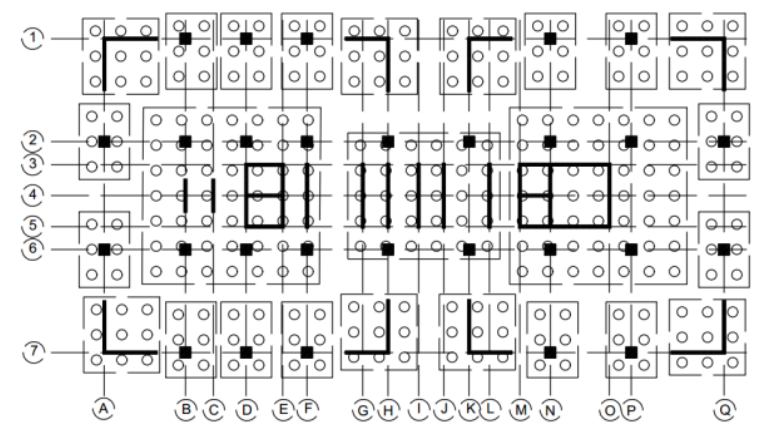

Gambar 15. Denah Pilecap

\subsection{PERHITUNGAN TIANG PANCANG DAN POER} Spesifikasi Tiang Pancang
Dibagi menjadi 3 tipe tiang pancang kelompok: Tabel 1. Pengelompokan Tiang Pancang

\begin{tabular}{|c|c|c|}
\hline Tipe & Tipe 1 & Tipe 2 \\
\hline Pancang & $4 \mathrm{D} 1000-11 \mathrm{~m}$ & $9 \mathrm{D} 1000-$ \\
Poer & $5 \times 5 \times 1,5 \mathrm{~m}^{3}$ & $11,6 \times 17,6 \times 1,5 \mathrm{~m}^{3}$ \\
\hline Elemen & Tipe 4 & Tipe 3 \\
\hline Pancang & $30 \mathrm{D} 1000-11 \mathrm{~m}$ & $49 \mathrm{D} 1000-11 \mathrm{~m}$ \\
Poer & $12,5 \times 15 \times 1,5 \mathrm{~m}^{3}$ & $17,5 \times 17,5 \times 1,5 \mathrm{~m}^{3}$ \\
\hline
\end{tabular}

Penulangan poer masing- masing tipe:

Arah $\mathrm{x}=\mathrm{D} 29-125$, Arah $\mathrm{y}=\mathrm{D} 29-125$

Penulangan Tusuk Konde $=18$ D29-150mm
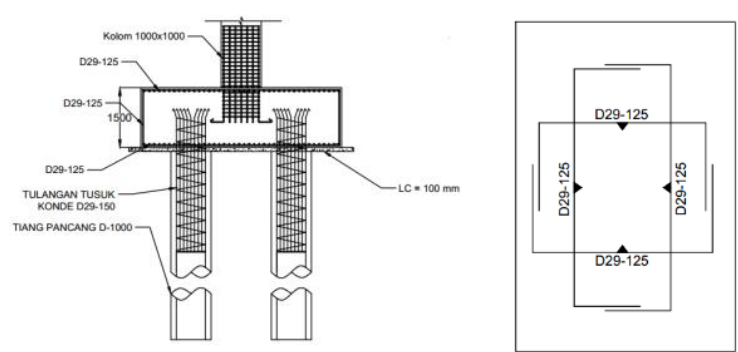

Gambar 16 Detail Tiang Pancang dan Poer X. METODE PELAKSANAAN

Metode pelaksanaan merupakan uraian mengenai komponen dan material pendungkung yang digunakna dalam pelaksanaan metode beton pracetak

1. Proses percetakan elemen pracetak dilakukan secara fabrikasi diluar situs proyek

2. Pengangkatan dan penempatan Tower Crane. Jenis Crane yang digunakan adalah POTAIN 160C dengan jarak jangkauan mencapai 33 meter dengan beban maksimum pada jarak tersebut 25 ton.

3. Metode pekerjaan elemen pracetak

a. Pemasangan dan pembuatan pilecap yang dilakukan terlebih dahulu kemudian erection shearwall pracetak dan kolom dilakukan yang kemudian dilanjutkan dengan grouting $N M B$ Splice Sleeve yang telah terpasang.

b. Pemasangan balok induk dan balok anak dilakukan dengan menggunakan konsol pendek dan 2 buah skafolding yang dipasang pada $1 / 4 \mathrm{~L}$ dari ujung-ujung balok.

c. Setelah balok induk dan anak sudah pada posisnya, dilakukan pemasang pelat lantai.

d. Pemasangan pelat lantai dan tangga diberi overtopping untuk membuat struktur lebih monolith.

\section{KESIMPULAN}

1. Perhitungan dimensi struktur baik primer dan sekunderdidasarkan pada SNI 2847:2013.

2. Analisa gaya dalam dilakukan menggunakan program bantu ETABS. Beban yang diinput pada permodelan adalah beban mati dan beban hidup sesuaidengan PPIUG 1983.

3. Penyambungan elemen pracetak menggunakan produk dari Peikko Group dan NMB Splice Sleeve. 
4. Pondasi direncanakn menggunakan tiang pancang dari WIKA beton dengan metode tegangan ijin dan pilecap berdasarkan tegangan ultimate

5. Hasil analisa struktur yang telah dilakukan pada Gedung Apartemen One East dituangkan dalam program bantu AutoCad.

Saran

1. Urutan pelaksanaan permodelan yang benar adalah dengan menentukan factor reduksi gempa terlebih dahulu terutama yang berhubungan dengan daktilitas sambungan.

2. Dalam perencanaan pracetak, perlu dipahami terlebih dahulu metode pelaksanaan konstruksi sebelum mendesain kebutuhan dimensi struktur.
3. Perancangan elemen pracetak dapat dibuat lebih efisien dengan melakukan perencanaan secara menyeluruh sehingga tidak asal langsung mengambil gaya terbes ar yang terjadi.

4. Diperlukan penelitian lebih lanjut terkait konsep sambungan Studi ini, terutama bila gedung terletak di daerah rawan gempa.

\section{DAFTAR PUSTAKA}

[1] A. A. Yee, "Social and Environmental Benefits of Precast Concrete Technology," PCI J., p. 16, 2001.

[2] O. S. D. Nakaki, "Development of Precast Concrete Shear W all System Requiring Special Code Acceptance," PCI J.,p. 122, 2011.

[3] K. A. Soudki, S. H. Rizkalla, and B. Leblanc, "Horizontal Connections for Precast Concrete Shear Walls Subjected to Cyclic Deformations Part 1 : Mild Steel Connections," PCI J., 1995. 